\title{
O PROTAGONISMO DOS BACHARÉIS EM DIREITO: a atuação dos irmãos Villela Tavares e o discurso político e juridico em Pernambuco (1836-1858)
}

\begin{abstract}
Alexsandro Ribeiro do Nascimento*
RESUMO: O presente trabalho tem o objetivo de discutir a movimentação política dos magistrados em Pernambuco por meio da atuação dos irmãos Joaquim Villela de Castro Tavares e Jerônimo Villela Tavares. O período analisado, entre 1836 e 1858, vai desde o começo do exercício público dos dois personagens relatados até a morte de Joaquim Villela. Através do método da micro história usamos o Arquivo da Faculdade de Direito do Recife, além de alguns periódicos como fontes para reconstruir a dinâmica entre os bacharéis no campo de concentração jurídica e também política. É pela relação estreita dos principais poderes do Império que se pode entender o funcionamento e os percalços da administração pública do país.
\end{abstract}

PALAVRAS-CHAVE: Bacharéis; Justiça; Pernambuco; Villela Tavares

\section{The role of the undergraduates in law: the performance of the brothers Villela Tavares and the political and legal discourse in Pernambuco (1836-1858)}

ABSTRACT: This paper aims to discuss the political movement of magistrates in Pernambuco through the actions of brothers Joaquim Villela de Castro Tavares and Jerome Villela Tavares. The analyzed period, between 1836 and 1858, goes from the beginning of the public office of the two reported characters until the death of Joaquim Villela. Through the micro-históry method we use the Recife Faculty of Law Archive, in addition to some journals as sources to reconstruct the dynamics among undergraduate in the field of legal and political concentration. It is by the close relationship of the empire's main powers that one can understand the functioning and mishaps of the country's public administration.

KEYWORDS: Undergraduates; Justice; Pernambuco; Villela Tavares

\section{El protagonismo de los licenciados en Derecho: la actuación de los hermanos Villela Tavares y el discurso político y jurídico en Pernambuco (1836-1858)}

RESUMEN: Este artículo tiene como objetivo discutir el movimiento político de los magistrados en Pernambuco por medio de la acción de los hermanos Joaquim Villela de Castro Tavares y Jerônimo Villela Tavares. El período analizado, entre 1836 y 1858, va desde el inicio del ejercicio público de los dos personajes susodichos hasta la muerte de Joaquim Villela. Por medio del método de la microhistoria, utilizamos el archivo de la Faculdade de Direito do Recife, además de algunas revistas como fuentes para reconstruir la dinámica entre los licenciados en el campo de la concentración jurídica y también política. Es a través de la estrecha relación de los principales poderes del Imperio que se puede comprender el funcionamiento y los percances de la administración pública del país. PALAVRAS CLAVE: Licenciados; Justicia; Pernambuco; Villela Tavares

\footnotetext{
* Mestrado em História pela Universidade Federal Rural de Pernambuco (UFRPE). Doutorando em História pela Universidade Federal da Bahia (UFBA). Contato: Rua José de Alencar, 522, CEP: 50070075Recife. PE, Brasil. Email: alexribeiro2@gmail.com. ORCID: https://orcid.org/0000-0001-9091-4874
} 
Ser bacharel em Direito no Brasil do oitocentos era uma função muito além de técnica e política. Era um simbolismo que deveria ser conservado como a manutenção da ordem. Como um ser responsável pelo bem coletivo que assegurava o cumprimento da lei e mantinha a unidade local. A presença de um magistrado, munido de beca preta ou sobrecasaca, era respeitada pela população local e servia como mediador de conflitos ${ }^{1}$. Alguns equipavam suas becas com utensílios bordados e importados de outros países para se diferenciarem dos padres, que utilizavam roupas parecidas.

Com as inaugurações das faculdades de Direito no Brasil após a independência nas cidades de São Paulo e Olinda vários personagens importantes para a administração do novo império que surgia sob a futura liderança do jovem D. Pedro II se especializaram na área jurídica e, por que não, política. Com as formações das primeiras turmas, já na década de trinta do século XIX, esses novos bacharéis ingressaram em cargos estratégicos como presidentes da província, promotorias, juízes de direito, chefes de polícia, além de ocuparem o Legislativo com postos de deputados provinciais, gerais e senadores ${ }^{2}$.

Muitos desses magistrados já faziam parte de grupos privilegiados na cena política e econômica do Brasil. Alguns possuíam formação jurídica na Universidade de Coimbra, mas a instalação de cursos de Direito no país ajudou a multiplicar o número de bacharéis. O título acadêmico era um diferencial na vida pública e possuía um simbolismo considerável dentro das relações sociais construídas entre personagens que estavam à frente das principais instituições governamentais.

Por ocuparem diversos cargos nas instituições policiais, jurídicas e políticas, estes bacharéis estavam inseridos no meio de uma rede de participação da vida pública, podendo ter acesso a vários espaços de poder. Tendo a chance de circular entre cargos políticos e nas províncias, podemos considerar que os magistrados foram um dos principais atores sociais do Brasil no século XIX ${ }^{3}$. Não somente por ocuparem as funções supracitadas, mas por regerem, formularem e aplicarem as leis, eles foram responsáveis por direcionar as normas estabelecidas no recente código criminal de 1830 e contribuíram para o processo de vigilância e punição das diversas camadas da sociedade do oitocentos ${ }^{4}$.

Estas leis regidas pelos bacharéis, no âmbito dos textos legais, não são pontualmente cumpridas existindo, muitas vezes, estilos diferentes de julgamento. Para Antonio Manuel Hespanha, a doutrina na área de Direito reconstrói fatos, silencia outros, e até cria realidades imaginárias, ou seja, os textos vão além das instituições e dialogam com outros espaços por diferentes grupos sociais ${ }^{5}$. Segundo o pesquisador português, as análises dos textos jurídicos 
não podem ser consideradas autônomas diante da complexidade do universo de diferentes atores sociais que aplicam e que são atingidos pela lei. Contudo, Hespanha não deixa de destacar o capital político e simbólico que os juristas possuem na mediação do Direito ${ }^{6}$.

Há de ressaltar que, apesar dos procedimentos de negociação entre membros de instituições jurídicas e policiais com micro poderes regionais, no qual os magistrados foram muitas vezes o fio condutor dessas relações, o Estado era quem ditava as regras ${ }^{7}$. Mesmo com a representatividade das lideranças locais, o poder de decisão era da Corte ${ }^{8}$.

Através dessas questões levantadas por Hespanha novas abordagens se abrem na historiografia do Direito, principalmente pelo aspecto humanista, no qual os magistrados aplicam a lei não apenas como objeto simplesmente normativo, mas sim como um instrumento de disciplina social, muitas vezes feito ao seu modo ${ }^{9}$.

É por conta dessas nuances que o bacharel fortalecia suas relações sociais e, como agentes condutores do Estado, eram quase sempre protagonistas nos processos de sociabilidade das instituições. Para José Murilo de Carvalho, os magistrados fizeram parte de uma "elite homogênea" que se formou primeiro em Portugal, depois no Brasil e estava isolada das doutrinas revolucionárias da França e Inglaterra ${ }^{10}$. A homogeneidade era garantida por fatores como a socialização, carreira e treinamento ${ }^{11}$. No entanto, mesmo com esse tipo de aprendizado, os operadores de Direito tiveram contato com diversas ideias que circulavam na Europa. A aversão ao iluminismo francês, por exemplo, não eram ignorados nas rodas de conversas e em artigos publicados em diversos periódicos da época, principalmente em Olinda $^{12}$.

É devido a multiplicidade de funções e de estarem inseridos em diversos campos de análise histórica, tais como social, política e jurídica que escolhemos trabalhar com a temática dos operadores de Direito no século XIX. Apesar de produções consolidadas por autores como Vanessa Spinosa, Andréa Slemian e Jonas Moreira Vargas, existe uma carência de análise histórica destes personagens em Pernambuco, no que tange as suas funções perante as instituições públicas $^{13}$.

Com isso, o objetivo deste trabalho é discutir a movimentação política e jurídica destes magistrados em Pernambuco no século XIX. Analisar as redes, as relações de poder, o discurso político e a produção intelectual desses bacharéis. Para isso, iremos utilizar como objeto a atuação dos irmãos Joaquim Villela de Castro Tavares e Jerônimo Villela Tavares. Esses dois personagens estão inseridos no turbilhão político e no aperfeiçoamento das instituições jurídicas da época na província. A análise será feita entre o ano de 1836, quando 
Joaquim Villela ocupou o cargo de lente na Faculdade de Direito de Olinda, até a sua morte no ano de 1858 .

Através desses personagens vamos procurar abordar como o Estado produz seu discurso legitimador pelas vozes jurídicas, seja impondo a ordem ou propagando suas ideias. A produção intelectual e o discurso jurídico dos Villela Tavares servem como um dos objetos de análise para entender como a atuação da justiça e da política andavam juntas e contribuíram para a multiplicidade da interpretação das leis. O ordenamento jurídico perpassa por esses tipos de atores sociais, que estão ligados por laços parentescos e pertencerem a grupos que já faziam parte da elite política e econômica local.

Para isso o presente trabalho irá tratar primeiro do perfil do alunado das primeiras turmas da Faculdade de Direito de Olinda, por conseguinte das diversas funções que foram encarregados aos bacharéis através da Reformulação do Código do Processo Criminal em 1841, e, por último, será analisado a atuação dos Villela Tavares e importância que estes tinham como atores políticos e jurídicos e de produtores de discurso intelectual na província pernambucana.

\section{O perfil dos primeiros bacharéis formados na Faculdade de Direito de Olinda}

As primeiras turmas na Faculdade de Olinda contavam com 50 alunos. A debutante formou 44 discentes. Estes, em sua maioria, já faziam parte da elite política do país. Depois de formados em 1832, muitos deles ocuparam cargos de destaque no novo governo que surgia com a chegada de D. Pedro II ao poder. Entre eles estava Eusébio de Queiroz Coutinho Mattoso da Câmara, que foi ministro da Justiça ${ }^{14}$.

Nesse grupo também estavam inseridos dois protagonistas da Insurreição Praieira, mas que atuaram de lados opostos: Jerônimo Martiniano Figueira de Melo e Joaquim Nunes Machado. O primeiro foi chefe da polícia de Pernambuco e comandou as tropas contra os rebeldes. Natural do Ceará, ele chegou a ser deputado pela província de origem e também por Pernambuco. O segundo era um dos líderes dos movimentos de 1848 e 1849. Foi juiz de direito em Goiana e deputado geral, sendo um dos mais participativos nas tribunas do parlamento - ele chegou a ser contra a maioridade de D. Pedro II. Morreu assassinado em combate na própria Praieira, no motim ocorrido no Recife, em fevereiro de $1849^{15}$.

Outro nome de destaque na primeira turma é Zacharias de Góes e Vasconcelos. Ele foi mais um quadro a chegar ao ministério no segundo reinado, na década de 1860, e também professor da Faculdade de Direito de Olinda ${ }^{16}$. Quem também assumiu uma das pastas no 
governo, como ministro da Justiça, em 1858, foi Sérgio Teixeira de Macedo, tendo ainda no currículo político um cargo de deputado geral ${ }^{17}$.

Os restantes dos bacharéis recém-formados possivelmente tiveram atribuições como juízes de direito, chefes de polícia e promotores. Afinal, surgia uma nova leva de magistrados formados no Brasil. Agora com o curso jurídico era o momento de construir o país com os operadores de Direito, os capacitados para tais funções.

Os magistrados recém-formados nas primeiras turmas dos cursos jurídicos do país ocuparam cargos nas capitais das províncias ou nas comarcas perto de sua região de origem. Muitos pediam demissão pouco tempo após ser encaminhados para vilas mais distantes. Os formados em Direito queriam estar mais próximos do centro político, e lugares como Recife, Olinda e Igarassu eram os mais procurados ${ }^{18}$. Na impossibilidade de conseguir boa localização, a solução era aguardar uma oportunidade para ser transferido. Esta vinha em geral através de auxílio de amigos ou de correligionários políticos já bem colocados ${ }^{19}$.

Por ser a única Formação de Direito da região, o curso de Olinda, localizado no Mosteiro de São Bento, recebia estudantes de diversas partes do Norte imperial ${ }^{20}$. Alguns jovens vinham de outras províncias do Sul do Brasil. Nos três primeiros anos, uma caravana de estudantes da Bahia veio aprender o estudo das leis na instituição.

Gráfico: Formados na Faculdade de Direito de Olinda 1832-1834 - Origem

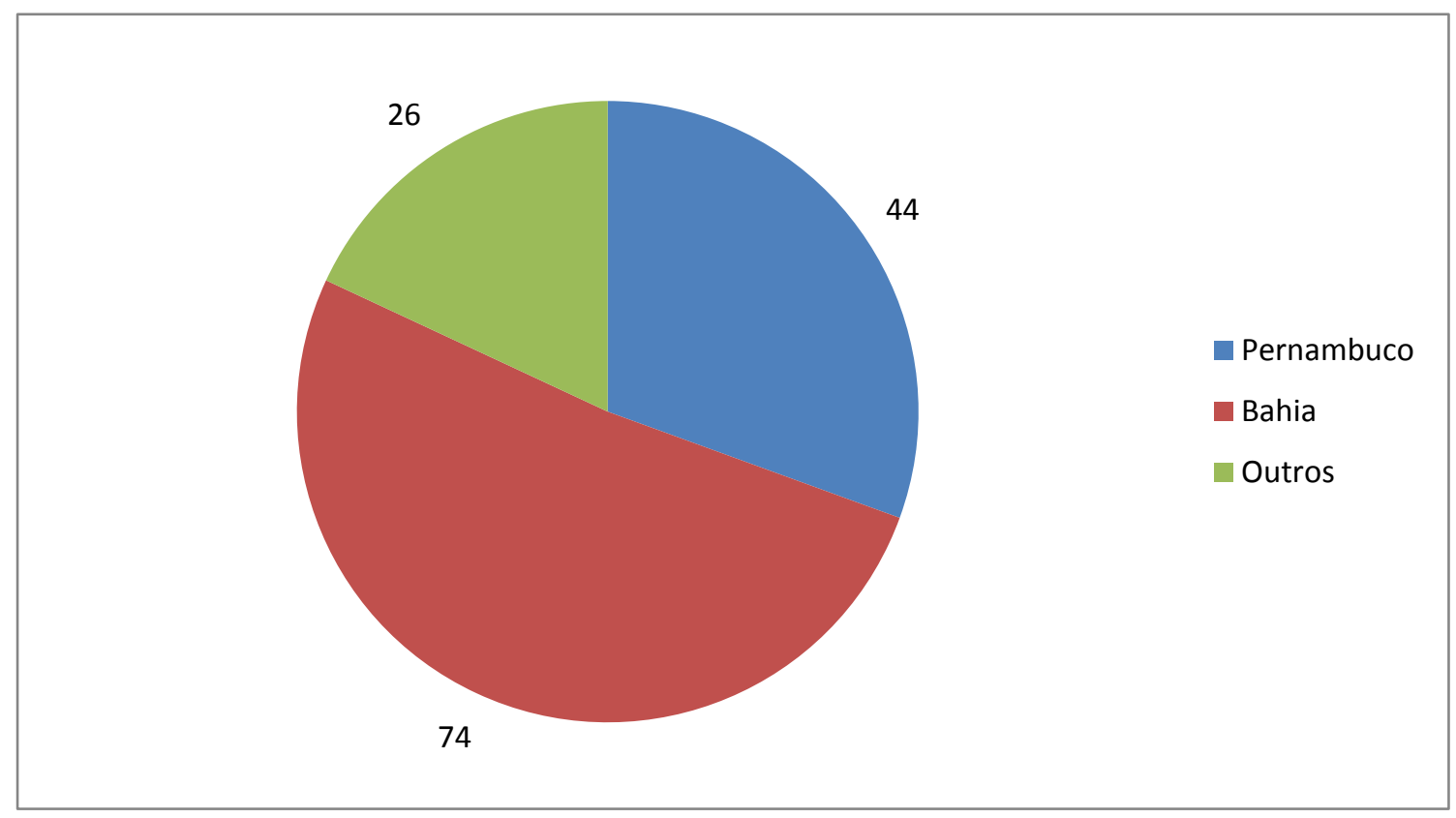

Fonte: Lista Geral de bacharéis e doutores (1828-1931). Arquivo da Faculdade de Direito do Recife 
O gráfico acima mostra que dos 144 estudantes formados nas primeiras turmas, 74 eram da Bahia, o que representava 51,30\% dos discentes mais até do que Pernambuco, local da instituição. A província teve nesse período 44 novos bacharéis, cerca de $30 \%$ do alunado. Os outros eram de outras partes do país como Ceará, Paraíba, Maranhão e o Rio de Janeiro. Isso corrobora a importância dos ensinamentos do espaço acadêmico na região que se disseminou pelo império. Estudar na Faculdade de Direito de Olinda era o objetivo de muitos dos filhos da elite política e econômica do Brasil. Circular por esses espaços era a chance de estar perto de outros membros que tinham acessos a cargos estratégicos e até a Corte.

\section{A multiplicidade de funções do bacharelismo no Brasil do oitocentos}

Com o prestigio adquirido na sociedade e com o status de ser formado em um dos únicos cursos de Direito do país, o bacharel recém-formado tinha o desafio de exercer diversas funções estabelecidas pelo seu treinamento adquirido na Faculdade. Com a reformulação do Código de Processo Criminal em 1841, muitos postos na área de justiça e também da polícia só podiam ser ocupados pelos operadores de Direito.

Os juízes letrados podiam assumir funções além da competência jurídica. As atribuições policiais e administrativas também faziam parte do cotidiano dos juízes, principalmente das comarcas mais distantes dos grandes centros. Com poucas pessoas competentes para assumir as ditas funções, os magistrados acabavam acumulando diversos serviços que poderiam comprometer no funcionamento da justiça.

Na reformulação de 1841 os juízes da paz tiveram suas atribuições restritas. Boa parte das suas funções foi repassada aos delegados, subdelegados e chefes de polícia. Esses oficiais podiam emitir ordens de busca, redigir processos contra acusados, escutar testemunhas e prender suspeitos de crime. A nomeação dos juízes municipais e promotores foi alterada sendo dispensadas as propostas das Câmaras Municipais, mas exigindo-se condições mais altas para a sua investidura.

Outra medida foi a criação de um lugar do chefe de polícia, com os delegados e subdelegados no município da Corte brasileira (localizada no Rio de Janeiro) e em todas as províncias. Segundo Nequete, os chefes de polícia seriam recrutados dentre os desembargadores e juízes de direito, e os delegados, dentre quaisquer juízes e cidadãos, seriam obrigados a aceitar os lugares que poderiam ser removidos ou transferidos para exercerem suas funções. Os juízes de direito também tiveram suas atribuições ampliadas: 
estes só seriam recrutados dentre bacharéis formados que tivessem servido com distinção nos cargos de juízes municipais, de órfãos ou de promotores públicos ${ }^{21}$.

Um dos pontos que poderia causar certa confusão na Reforma de 1841 versava sobre a transferência das atribuições do juiz da paz. Possivelmente os juízes municipais e membros da polícia deviam discutir quem era o responsável a realizar as funções dos juízes da paz, que tiveram seu cargo extinto. Como pode ser observado na tabela abaixo, a competência era muito semelhante tanto para os policiais quanto para os próprios juízes municipais:

Tabela I - Funções dos juízes municipais, de direito e chefes de polícia na Reformulação do Código de Processo Criminal em 1841

\begin{tabular}{|c|c|c|}
\hline Juízes Municipais & Juízes de Direito & $\begin{array}{l}\text { Chefes de Polícia (delegados } \\
\text { e subdelegados) }\end{array}$ \\
\hline $\begin{array}{l}\text { Art. } 17 \text { Compete aos juízes } \\
\text { municipais } \\
\text { § } 2 \text { - As atribuições criminais } \\
\text { e policiais que competiam aos } \\
\text { Juízes de Paz; }\end{array}$ & $\begin{array}{l}\text { Art. 25 Compete aos juízes } \\
\text { de direito } \\
\S \text { 2. Julgar as suspensões } \\
\text { postas aos Juízes Municipais } \\
\text { e Delegadas. }\end{array}$ & $\begin{array}{l}\text { Art. } \mathbf{6}^{\mathbf{0}} \text { As atribuições } \\
\text { criminais e policiais que } \\
\text { atualmente pertencem aos } \\
\text { Juízes de Paz, e que por esta } \\
\text { Lei não forem especialmente } \\
\text { devolvidas ás Autoridades, } \\
\text { que creia, ficam pertencendo } \\
\text { aos Delegados } \\
\text { Subdelegados. }\end{array}$ \\
\hline $\begin{array}{l}\text { Art. 17 } \$ 3 \text { - Sustentar, ou } \\
\text { revogar, ex-offício, as } \\
\text { pronuncias feitos pelo } \\
\text { Delegados e subdelegados }\end{array}$ & $\begin{array}{l}\text { Art. } 26 \S 2 \text { - Todos os crimes } \\
\text { que tiverem sido sentenciados } \\
\text { pelos Juízes Municipais, } \\
\text { Delegados e Subdelegados; } \\
\text { procedendo contra eles, se } \\
\text { acharem que condenarão ou } \\
\text { absolverão os réus por } \\
\text { prevaricação, suspeita ou } \\
\text { suborno }\end{array}$ & \\
\hline
\end{tabular}

Fonte: Lei 261/41 | Lei No 261, de 3 de dezembro de 1841.

Podemos perceber que o Artigo 17 e inciso dois dos juízes municipais (também citado no quadro I eram praticamente iguais ao artigo seis das atribuições do chefe de polícia, eles (juízes e polícia), poderiam atribuir funções que competiam aos juízes da paz. O juiz de direito estava acima na hierarquia e podia vetar qualquer tipo de sentença dada pelos juízes municipais, delegados e/ou subdelegados.

A execução das normas realizadas pela reforma de 1841 (e também as anteriores como o Código Criminal de 1830 e o Código de Processo Criminal de 1832) teve resistência das elites locais. Este grupo não tinha uma relação amistosa com os membros do governo central. Como a Corte se instalou no território brasileiro apenas no século XIX, os grupos locais 
estavam à frente, mesmo que indiretamente, das rédeas do poder administrativo e político. $\mathrm{O}$ maior exemplo disso foi à implantação da Câmara nas comarcas do Brasil, ela acabou representando a institucionalização do poder local ${ }^{22}$.

De acordo com Elaine Leonara, por conta desse atrito entre governo e poder local, o processo de fortalecimento do Estado foi lento. $\mathrm{Na}$ administração judiciária, a mudança ocorrida no século XIX foi organizada tendo como base a antiga estrutura joanina. No entanto, em lugares que havia poucos magistrados não existiu uma alteração significativa ${ }^{23}$. Era preciso ter quadros suficientes para exercer a função jurídica e, por conta disso, algumas pessoas da "velha" magistratura foram mantidas nos cargos, o que pode justificar resistência aos novos moldes jurídicos que vieram com o Código do Processo Criminal.

Por conta dessa lentidão, a modernização, segundo Mozart Linhares, foi moderada, amenizada, e deixada de lado em muitas regiões. Uma das razões disso foi a política de restrição das elites locais que continuou vigorando por bastante tempo. Era a coação do interesse familiar. Esses grupos não queriam perder os privilégios que tinham nas instituições e, com isso, a organização política-administrativa do Império manteve-se excludente ${ }^{24}$. Dimas José Batista chega a dizer que o Estado brasileiro todo-poderoso era uma "ficção"25. Entretanto, para ele, a Corte tentava de toda maneira fazer valer a pena seus princípios.

As funções jurídicas também se estendiam a outros desempenhos como juiz de órfãos e de juízes dos africanos - os magistrados pernambucanos se intitulavam dessa forma nos ofícios enviados ao presidente da província e ao Ministério da Justiça sobre as questões referentes à concessão dos africanos livres a particulares ${ }^{26}$.

Além dos cargos de justiça e polícia, os bacharéis também podiam acumular cargos políticos como de vereadores, deputados gerais e/ou províncias, e senadores. Outros seguiam a carreira acadêmica lecionam em cursinhos preparatórios para o ingresso na Faculdade de Direito e também como lentes nesta própria instituição de ensino.

Com tantos cargos disponíveis para serem ocupados, a análise da atuação do bacharel pode se estender a vários campos de análise no âmbito historiográfico. No geral, o bacharel em direito poderia ter o cargo de juiz de direito, juiz municipal, juiz de órfãos (que englobava a função de juiz dos africanos), desembargador, promotor, professor, lente da Faculdade de Direito, vereador, deputado geral e/ou provincial, senador, chefe de polícia, delegado e subdelegado. Só apenas com a Lei dos Círculos de 1855 os magistrados foram proibidos de ser candidatos em seus distritos, caso estivessem à frente de alguns cargos no âmbito jurídico. 
Isso comprova que, trabalhar com os magistrados no oitocentos é ter um leque de possibilidades na abordagem histórica, seja no campo das ideias, da política e do social ${ }^{27}$.

\section{A produção intelectual e o discurso político dos Villela Tavares}

Pela acumulação de cargos e as diferentes abordagens no campo da História, a análise de diversos bacharéis é importante para compreender o funcionamento da Justiça, polícia e a vida acadêmica do oitocentos. Por conta da multiplicidade de funções, vários magistrados podem fazer parte de abordagens de espaços distintos, seja em Pernambuco ou em outras regiões do país.

Nesta parte do trabalho pretendemos analisar a atuação de dois personagens que tiveram uma participação significativa nas instituições públicas de Pernambuco: Jerônimo Villela de Castro Tavares e Joaquim Villela de Castro Tavares ${ }^{28}$. O primeiro foi deputado geral, docente da Faculdade de Direito de Olinda e um dos participantes mais ativos da Insurreição Praieira, no qual ficou famoso pela quadra "Quem viver em Pernambuco/Deve ser desenganado/ Que ou há de ser Cavalcanti/ Ou há de ser cavalgado”. O segundo foi juiz, deputado, presidente da província do Ceará e professor da mesma instituição educacional de Pernambuco $^{29}$.

Tratar estes dois personagens que tiveram participação significativa nas movimentações jurídicas, e sobretudo políticas nos acontecimentos da província pernambucana elucida algumas questões a respeito das movimentações partidárias, dos debates sobre a liberdade e da legitimidade das instituições e diferentes projetos políticos. As suas formações intelectuais e experiências na vida pública os tornam contribuintes para redefinir os debates nos anos seguinte do segundo reinado.

\section{“Façam como eu, não poupo ninguém. A minha opinião é esta" ${ }^{30}$. As movimentações políticas de Jerônimo Villela de Castro Tavares}

Jerônimo Villela nasceu no Recife em 8 de outubro de 1815 e faleceu em 25 de abril de 1869. Era filho de Jerônimo Villela Tavares e Rita Maria Theodora de Castro. Entrou na Faculdade de Olinda aos 16 anos e obteve o grau de bacharel em 1835, mesmo ano em que conseguiu o grau de doutor e prestou concurso para concorrer a uma vaga de professor substituto na mesma faculdade, o que não foi possível por não ter a idade exigida pela lei. Ele só conseguiu ingressar como docente em $1844^{31}$. 
Como deputado geral criticou, ao lado de liberais como Nunes Machado, o governo da província e grupos dominantes da época, em especial os Cavalcantis. Foi também promotor público nas comarcas de Bonito, Rio Formoso e Garanhuns. Exerceu ainda o posto de secretário da presidência das províncias da Paraíba e de Pernambuco ${ }^{32}$.

Já atuando como deputado provincial era uma das vozes mais ativas na Casa Legislativa de Pernambuco. Convenceu, por exemplo, seus colegas parlamentares a apoiarem o projeto de aumento da força policial de 200 para 800 praças. Segundo Villela, a medida era necessária para garantir a segurança da população e a legitimidade das autoridades pernambucanas.

Senhores, não sei porque rasões, não sei por que fatalidade, ha indivíduos que se não se contentam com a sua posição social; indivíduos que não se contentam com a sua autoridade regular que pelas leis do paiz lhes he conferida; (apoiados) eu sei que o desejo de augmentar o poder e de praticar mesmos abusos he quasi natural ao homem; mas esses desejos devem ser reprimidos pela educação e pela moralidade, $o$ que faz com que cada um se contenha no circulo de suas attribuições ${ }^{33}$.

Vale lembrar que o presidente da província na época era aliado do Jerônimo Villela. Simpático aos praieiros, Chichorro da Gama era defendido por esse grupo políticos em rodas de conversas nos botequins, cafés, palanques de rua e, claro, na arena política. Diante disso, quando Villela comenta no texto destacado "indivíduos que não se contentam com a sua autoridade regular que pelas leis do paiz lhes he conferida”, ele está se referindo também a bancada de oposição ao governo.

Entre outros debates que participava nas arenas políticas a aversão ao estrangeiro era um dos assuntos mais debatidos. $\mathrm{O}$ antilusitanismo predominava entre as figuras ligadas ao partido da praia. Para estes, os portugueses não podiam ocupar cargos e deixar os brasileiros desempregados. Em sessão na Assembleia Provincial, Jeronimo Villela atacava medidas que pudessem colocar estrangeiros em funções públicas.

(...) pois é preciso, que a assembleia provincial determine, que os que não forem cidadãos brasileiros não podem ser empregados públicos? (...) Só se foi para censurar algum governo, algum presidente, que, ultrapassando os limites, que lhe eram marcados e calçando aos pés a constituição e as leis, nomeou para empregos da província, não só a estrangeiros, senão a estrangeiros reconhecidamente inimigos do Brazil. $^{34}$

Como um dos líderes da Insurreição Praieira, ele foi preso e condenado à prisão perpétua no ano seguinte, onde foi enclausurado no presídio de Fernando de Noronha e depois na Fortaleza do Brum. Ele era aliado de uma das principais referências dos "homens da praia”. Ao lado do deputado Joaquim Nunes Machado foi protagonista de vários debates na 
Assembleia Provincial e no parlamento do Rio de Janeiro. Com a morte de Machado no campo de batalha em 1848, no centro do Recife, Villela se tornou uma das principais ameaças ao governo ${ }^{35}$.

Enquanto esteve aprisionado seu irmão, Joaquim Villela era bastante prestigiado pelo governo chegando a receber a Ordem da Rosa em 1849. Este tomou rumos diferentes no campo político, principalmente nas divergências de ideia que tinha com seus antigos aliados na província pernambucana. Entre os seus agora opositores estava o próprio Jerônimo Villela. Naquele momento, o mesmo palanque não cabia mais aos dois.

Depois de preso, Jerônimo Villela foi destituído de seu cargo de professor na Faculdade de Direito. Em 1851 obteve o perdão de sua pena e no mesmo ano foi restituído no cargo. Em 1855 passou a ser professor titular da cadeira civil. No mesmo ano assumiu a disciplina de Direito Eclesiástico, no qual virou especialista na área, chegando a lançar o Compêndio de Direito Eclesiástico, obra de auxílio aos estudantes. O livro chegou a ser debatido também no curso jurídico de São Paulo ${ }^{36}$.

$\mathrm{Na}$ apresentação do compêndio, Jerônimo Villela comentou que foi uma das primeiras pessoas a apresentar este tipo de trabalho para a sociedade. No entanto, seus compromissos políticos tinha o impedido de terminar a obra. Ele voltou a escrever o livro como uma forma de homenagem póstuma ao seu irmão, Joaquim, falecido precocemente.

(...) fomos, pois, o primeiro que se animou a apresentar ao paiz um compendio de direito ecclesiastico, não obstante a nossa deficiência, e logo depois, em 1856, o nosso bom irmão e amigo, o Dr. Joaquim Villela, as suas Instituições de Direito Publico Ecclesiastico, que ficaram incompletas, mesmo na introdução, pela morte prematura, que o arrebentou d'entre nós ${ }^{37}$

Ainda no âmbito político, Jerônimo Villela chega a ser cotado como uma das lideranças dos liberais após a Insurreição Praieira. Seu nome é lembrado para estar à frente do partido liberal, tendo o apoio de Nabuco de Araújo contra Nascimento Feitosa.

Era preciso que houvesse a convicção de um chefe, a fé dos proselytos; a suspeita mata toda a esperança; a populaça vê no Villela não a própria convicção, mas a inspiração de V Ex., que não pôde querer o interesse d'elles contra os seus interesses politicos. A coisa, pois, se reduz a uma questão de individualidades : se V Ex. fosse o chefe, o partido estaria formado ou extremado; não tem V. Ex. essas idéas, não aspôde inspirar. Infelizmente no certame vencerá o Feitosa, que tem mais fé do que o Villela, que é suspeito; infelizmente dominará ainda o Feitosa e com elle a anarchia. Em verdade ahi não ha mais partido Liberal; ha anarchistas, demagogos que conspiram contra qualquer actualidade, que querem derrubar tudo, inclusive o poder que elles pretendem e que tornam impossível ${ }^{38}$ 
Nabuco de Araújo previu a escolha de Nascimento Feitosa frente ao partido liberal. O pai de Joaquim Nabuco ainda apoiou Jerônimo Villela nas eleições de 1856, no qual conseguiu o cargo de deputado ${ }^{39}$. Após a morte de Joaquim Villela, o antigo líder praieiro voltou a se dedicou a vida acadêmica. Ele assumiu a disciplina de Direito Eclesiástico que antes era professorada pelo seu irmão até a sua morte, no ano de 1869.

\title{
"Sem força não se garante a segurança e propriedade" ${ }^{40}$ : a atuação de Joaquim Villela
}

Joaquim Vilella de Castro Tavares nasceu em 7 de dezembro de 1816, na cidade do Recife. Seus pais eram Jerônimo Vilella Tavares, irmão do também jurista Jerônimo Vilella de Castro Tavares, e Rita Maria Theodora de Castro Tavares. Em 1836 recebeu o grau de bacharel em direito pelo Curso Jurídico de Olinda e poucos anos depois foi contemplado com o grau de doutor. Nesse mesmo curso, quando uma das cadeiras ficou vaga, em 1841, ele se candidatou a ocupa-la e, após aprovado, entrou para o corpo docente como substituto aos 23 anos.

O irmão mais novo de Jerônimo Villela lecionou nas disciplinas de Direito Comercial, Direito Administrativo, Direito Eclesiástico ${ }^{41}$. Nesta última contribuiu com a obra “Instituições de Direito Público Eclesiástico". No livro, o docente critica o racionalismo "que considera a razão independente de Deus e dos homens" "42. A valorização da igreja romana é o principal argumento de sua obra. Segundo ele, a instituição era sinônimo de "unidade, santidade, catolicidade e apostolicidade" $"$.

\begin{abstract}
As lutas excitadas pelo racionalismo fizeram melhor o espirito do Cristianismo e lhe grangearam maior admiração-, e a razão privada da luz, que somente a completa, arrancada de sua raiz, e desprendida do centro, que a deve atrair, querendo ultrapassar os limites da experiência e da ideia, ir além de todas as leis da evidencia, descortinar as regiões do invisível, do incompreensível, do infinito, e penetrar nas alturas inacessíveis em que, segundo o Apóstolo habita Deus, obscurecesse-o, enfraquece-o, cambaleou, como um homem ébrio, caiu, debateu nas agonias do desespero no meio das mais espessas trevas e produziu o mais completo cepticismo $^{44}$.
\end{abstract}

Além da vida acadêmica, Joaquim Vilella exerceu uma carreira política de notoriedade. Chegou a ser deputado geral e provincial, e em 1853 foi nomeado presidente da província do Ceará. Na Assembleia Provincial em Pernambuco tinha discursos em prol da propriedade individual e na segurança pública. Para ele, a "força" do Estado era a garantia para ajudar a população nesses quesitos. 
(...) o cidadão pernambucano não tinha segura nem a vida, nem a sua propriedade; nas ruas mais publicas da cidade se assassinava e se assassinava impunemente; quadrilhas de salteadores existiam nas estradas, e até nos subúrbios da capital; o roubo de escravos, como é sabido, subiu extraordinariamente; chegou a um ponto horrível; ninguém podia ter seguro o seu escravo $(. . .)^{45}$

A ideia de propriedade defendida por Joaquim Villela era um argumento de defesa aqueles que queriam a manutenção da escravidão. Nesse caso, as posses (terras e escravos), deveriam ser um direito legitimado em toda a sociedade. Algo que se tornou quase senso comum no Brasil pós-independência. Ou seja, a classe política ascendente na formação do novo Estado brasileiro, muitos destes espelhados em preceitos franceses e norte-americanos, preservaram a condição escravocrata ${ }^{46}$.

A solução para evitar qualquer imprevisto para a segurança pessoal e também da questão da propriedade era, segundo Joaquim Villela, o uso da força. "Uma força, que não é sufficiente para espalhar-se por todos os lugares da província, não pode garantir o cidadão em qualquer parte, que se queiram perpetuar desta natureza" ${ }^{\text {"47 }}$.

Joaquim Villela foi bastante crítico dos praieiros os condenando pelos motins que ocorriam na província no final da década de quarenta. Chegou a chamar os membros deste partido de corruptos. Ele repelia os atos das pessoas que contestavam a autonomia do Estado imperial. Também rebateu a atuação do jornalista Borges da Fonseca, que se tornou um dos principais líderes movimento.

Joaquim foi um dos fundadores do partido praieiro em Pernambuco, mas acabou indo para oposição depois de não ter sido escolhido para compor uma chapa que iria concorrer a Assembleia Geral. Entre os nomes selecionados para concorrer ao pleito estava a do seu irmão, Jerônimo Villela. Por conta de sua postura contra os seus antigo aliados foi chamado de "Caim”, em referência bíblica, por trair o seu irmão.

(...) eu, não querendo acompanhar esse carro julguei deve fazer opposição a aqueles que erão causa de que a imortalidade progredisse tão espantosamente (...) Mas, Sr. Presidente, o que aconteceu? (...) um homem, Sr. Presidente, que havia denominado Caim a seu próprio irmão, e o havia repudiado em nome do pai $^{48}$

Mesmo com um discurso de fidelidade ao governo e proclamado nas arenas políticas, ele tentou ajudar o irmão a ser absolvido de sua condenação depois do episódio praieiro. Nesse caso, o interesse profissional, como em muitos outros, o interesse pessoal e familiar andava juntos. 
Como presidente da província do Ceará enfrentou uma forte oposição. Voltou a Pernambuco e era citado como um dos nomes que poderia acabar com a hegemonia dos Cavalcantis $^{49}$. No entanto, ele só consegue chegar a sexta suplência nas eleições de 1852 para deputado provincial ${ }^{50}$.

Também publicou algumas composições literárias, dentre as quais destacava-se nos gêneros satírico e jocoso. Ele era presidente honorário da sociedade acadêmica Atheneu Pernambucano, composta por estudantes e bacharéis em direito, e que contava com um jornal do mesmo nome.

Joaquim Vilella faleceu em 11 de março de 1858, aos quarenta e dois anos de idade. Os jornais diziam que ele morreu por "moléstias". Seu velório ocorreu na Matriz da Boa Vista reuniu várias personalidades locais, entre eles o Barão de Camaragibe, diretor da Faculdade de Direito da época ${ }^{51}$.

\section{Conclusão}

Diante do desempenho em diversos locais, dos discursos feitos nas arenas políticas, e dos debates com outros atores sociais que contribuíram para a formação do pensamento político no país dentro do seu tempo e espaço, pelo menos até a Reforma Judiciária de 1871, a análise sobre os magistrados ainda carece de estudos no campo historiográfico. A escolha da atuação dos Villela Tavares se tornou mais crível diante da documentação disponível pelo Arquivo da Faculdade de Direito do Recife e do projeto Memória Acadêmica da mesma instituição.

Outros nomes que fizeram parte do campo político e da produção intelectual de Pernambuco ainda carecem de análises mais aprofundadas. Identificar e compreender a movimentação desses atores jurídicos e/ou políticos é fundamental para preencher lacunas no que tange a história das ideias, da história política e social da província pernambucana.

Como estes magistrados circulavam por várias províncias e também pela Corte, além de muitos tinham um diálogo permanente com a elite local, analisar as suas movimentações e discursos é um dos ponto-chaves para abordar caminhos ainda não preenchidos na historiografia.

E ainda: estes magistrados foram responsáveis por diversas obras no oitocentos. Seja no meio acadêmico ou pela literatura divulgada nos periódicos, os bacharéis possuem uma vasta produção intelectual no qual versavam sobre várias temáticas, sobretudo a área política. 
Analisar esse material é identificar o discurso de uma significativa parte da elite do país. No que eles pensavam e agiam sobre a administração pública, a economia e demais grupos da sociedade. Compreender a atuação desses personagens é também avaliar como esses atores sociais se relacionavam com escravos, "pobres", comerciantes e outras camadas que faziam parte do século XIX. Se os Operadores de Direito ditavam a lei, cabe identificar quem era afetado com suas decisões, seja através da aplicação da justiça e até pelos seus discursos políticos.

É nesse contexto de implementação dos poderes soberanos que se pode elucidar, na luz da história, o quanto a luta pelos direitos individuais passaram por resistências no século XIX. Com isso, é possível perceber ${ }^{52}$ o quanto a universalização dos direitos era problemática e distante. E o discurso jurídico e político dos magistrados colaborava para a manutenção deste cenário censitário, sexista e escravista. Isso comprova que a própria noção de justiça ainda estaria longe de ser elucidativa para considerável parte da sociedade durante as primeiras décadas do Brasil pós-independência.

\section{Notas}

\footnotetext{
${ }^{1} \mathrm{O}$ antropólogo Georges Balandier utiliza desse símbolo de ordem e unidade para explicar a representação de um soberano. Usamos esta ideia para retratar o bacharel em Direito por conta da representatividade jurídica e política que este possuía no Brasil do século XIX. Cf: BALANDIER. George. O poder em cena. Brasília. UNB. 1982. Sobre as vestimentas dos bacharéis ver em: FREYRE, Gilberto. Sobrados e Mucambos. Rio de Janeiro: Editora Record, 1990. p. 575-585

${ }^{2}$ Em meados do século XIX, o termo bacharel, junto com o magistrado, podia ser utilizado por pessoas que já haviam exercido em algum momento de sua vida a função de profissional da lei. A nossa preocupação é distinguir esse cargo e focar somente nos formados em Direito. Ver conceito de bacharel em CARVALHO, José Murilo de. A construção da ordem: a elite política imperial. Rio de Janeiro: Campos. 1980, p. 217

${ }^{3}$ De acordo com Jonas Moreira Vargas, as redes devem ser empregadas como vínculos de duração limitada. Para ele o historiador precisa identificar as redes enquanto elas estiveram funcionando, pois do mesmo jeito que elas são construídas, elas podem ser rompidas após "cumprirem" seus resultados pessoais e coletivos. Já para Maria de Fátima Gouvêa, a ideia de rede pode ser entendida como "um conjunto de conexões recorrentes, capazes de alterar ou definir estratégias, bem como o curso dos acontecimentos num dado lugar e época". Cf: VARGAS, Jonas Moreira. Entre a paróquia e a Corte: a elite política do Rio Grande do Sul (1850-1869), Santa Maria: UFSM, 2007; GOUVÊA, Maria de Fátima S. "Redes governativas portuguesas e centralidades régias no mundo português, c. 1680-1640”. In: FRAGOSO, João \& GOUVÊA, Maria de Fátima S. Na Trama das Redes. Rio de Janeiro: Civilização Brasileira, 2010.

${ }^{4}$ Marta Irurozqui Victoriano tece uma breve explanação sobre uma compreensão dual das instituições na América Latina no século XIX. Dentro de suas análises podemos trazer para a questão brasileira a questão "do instituído e do instituto" e três ideias sobre os processos do Estado: como o seu aspecto multidirecional; os diferentes níveis de interação social; e os resultados inconclusivos na medida em que sua formação e aplicação sempre envolvem poderes que, em maior ou menor grau, desativam sua inter-relação com a sociedade. Cf: IRUROZQUI, Marta. "Presentación. La institucionalización del Estado en América Latina. Justicia y violência política en la primera mitad del siglo XIX”. In: Revista Complutense de Historia de América. 2011, vol. 37.
} 


\begin{abstract}
${ }^{5}$ HESPANHA, Antônio Manuel. Da Iustitia à disciplina: textos, poder e política penal no Antigo Regime" Justiça e litigiosidade: História e prospectiva, Lisboa, Fundação Calouste Gulbenkian, 1993. p. 494

${ }^{6}$ HESPANHA, Antônio Manuel. Op Cit p. 497

${ }^{7}$ Para Laura de Mello e Souza, Hespanha valoriza mais as elites locais, desconsiderando o poder do monarca nas relações estabelecidas com seus súditos na colônia. Trazemos essa análise de Hespanha e a crítica de Laura de Mello e Souza também para o Brasil pós-independência que ainda adotava das práticas portuguesas no seu aparato institucional. Cf: SOUZA, Laura de Mello. O Sol e a sombra: política e administração da América
\end{abstract} Portuguesa do século XVIII. São Paulo. Companhia das Letras. 2016.

${ }^{8}$ Nossa abordagem e crítica sobre essa ideia descentralizadora já no século XIX também atinge a historiadora Mirian Dolhnikoff. Para esta, o projeto federalista saiu vencedor na construção do Estado nacional. Uma tese bastante contestada uma vez que não se deve aceitar que havia uma autonomia política com feições federativas. Cf: DOLHNIKOFF, Mirian. O pacto imperial: origens do federalismo no Brasil do século XIX. São Paulo: Globo. 2005.

${ }^{9}$ É importante distinguir as concepções de Direito e Justiça tratadas na presente pesquisa. O Direito é abordado aqui dentro das ideias mais gerais do Estado. O Direito é uma espécie de regulação, enquanto a Justiça é uma qualidade, que pode ser exteriorizada por meio da ação de um indivíduo. A justiça vai além das regras do Direito, dos atos administrativos, ela pode agir em múltiplas ações e atribuir a cada qual aquilo que lhe é devido. Cf: ANTUNES, Álvaro Araújo. As paralelas e o infinito: uma sondagem historiográfica acerca da História da Justiça na América Portuguesa. Revista de História São Paulo, № 169, p. 21-52, julho / dezembro 2013

10 Diferente de alguns autores, como Maria Fernanda Baptista Bicalho, que ampliam o conceito de elite a diversos campos de análise, abordando a atuação de grupos ligados ao meio agrário, comercial e administrativo, levando a uma dispersão sobre o entendimento do que pode ser considerado "a elite" e de que forma ela atuava, iremos usar os conceitos de Antônio Manuel Hespanha e Flávio Heinz. Para o primeiro todas as pessoas, de algum modo, são pertencentes à elite porque "todos temos algum grupo que nos reconhece, para o bem ou para o mal, como detentores de uma legitimidade para dirigir em alguns dos planos da inter-acção social”; Já Flávio Heinz relata que a perspectiva sobre estes grupos é suficientemente aberta para ser utilizada em diversos tipos de investigações. Esse tipo de análise ajuda em um tratamento sociológico das elites. É um estudo que não se afasta da perspectiva histórica. Cf: BICALHO, Maria Fernanda. "Elites coloniais: a nobreza da terra e o governo das conquistas. História e historiografia”. In: MONTEIRO, Nuno G. F. et alli (org.). Optma Pars. Elites IberoAmericanas do Antigo Regime. Lisboa: Imprensa de Ciências Sociais, 2005; HEINZ, Flávio M. (org). Por outra história das elites. FVG editora. Rio de Janeiro. 2006; HESPANHA, Antônio Manuel. Governo, elites e competência social: sugestões para um entendimento renovado da história das elites. In BICALHO, Maria Fernanda. FERLINI, Vera Lúcia Amaral (orgs.) Modos de Governar. Ideias e Práticas Políticas no Império Português - séculos XVI a XIX. São Paulo. Almeida, 2005.

${ }^{11}$ CARVALHO. Op. cit, p. 38

${ }^{12}$ Em 1824, quatro anos antes da instalação do curso jurídico, a própria cidade de Olinda contava com um Seminário, que entre suas cadeiras se destacava a de língua francesa. Além disso, a expressão "o Império das Luzes" era citado nos jornais da época. Como a província tinha passado por eventos de caráter separatista como a Revolução Pernambucana de 1817 e a Confederação do Equador - tais acontecimentos beberam do iluminismo da França -, não é de surpreender que os ideias franceses ainda faziam parte do debate intelectual da época. E ainda: a preocupação com o saber e a utilização do iluminismo como prática dos novos estudantes ficou evidente no discurso feito no dia da inauguração da Faculdade de Direito de Olinda, pelo diretor interino Doutor Lourenço José Ribeiro. “(...) estão abertas nessa província os tesouros da sabedoria. Os jovens e caros concidadãos devem procurar as fontes das luzes”. Cf: VEIGA, Gláucio. História das ideias da Faculdade de Direito do Recife. Recife. V. 1. Ed. Universitária, 1980, p. 235

${ }^{13}$ Vanessa Spinosa possui trabalhos referentes a cultura política no Brasil império através da formação jurídica. Ela comenta que a produção normalizadora do direito no Brasil está associada as práticas sociais. E ainda que "toda a projeção de um sistema judiciário feita no estado teve que lidar com o risco de sua recepção". Já Andréa Slemian discute em sua tese a importância da implementação das reformas jurídicas após a independência como condição para o funcionamento da máquina pública. Enquanto Jonas Moreira Vargas aborda a questão da elite do Rio Grande do Sul, dentre os grupos jurídicos e políticos. Cf: SPINOSA. Vanessa. A lei dos homens: formação jurídica e cultura política no Brasil império. Passagens. Revista Internacional de História Política e Cultura Jurídica, Rio de Janeiro: vol. 3, no.3, setembro-dezembro 2011, p. 486-502; SPINOSA, Vanessa. Vocação para a justiça: o serviço público como missão cidadã (Brasil-1840-1889). Tesis Doctoral. Universidade de Salamanca. Salamanca. 2016. p, 28 ; SLEMIAN, Andréa. Sob o império das leis: Constituição e unidade nacional na formação do Brasil (1822-1834). Tese. História. USP. São Paulo. 2016; VARGAS. Op, cit. 2007

${ }^{14}$ BEVILÁQUA, Clóvis. História da Faculdade de Direito do Recife. Recife: EdUFPE, 2012, p. 50. 
15 BEVILÁQUA. Op, cit. p. 51; CADENA, Paulo Henrique Fontes. O vice-rei: Pedro de Araújo Lima e a governança do Brasil no século XIX. Tese (doutorado). UFPE. 2018, p. 120.

${ }^{16}$ CADENA. Op, cit. p 121.

${ }^{17}$ BEVILÁQUA. Op, cit. p. 51.

${ }^{18}$ Diferente da nossa abordagem sobre a locação dos magistrados, Vanessa Spinosa afirma que bacharéis do Rio Grande do Norte e da Paraíba do Norte no período do oitocentos aceitavam tomar posse de cargos em locais considerados mais periféricos por questões patrióticas. Cf: SPINOSA. Vanessa. "Da simples abnegação de cidadãos: serviço público e o judiciário oitocentista". In: II Encontro Internacional da Sociedade Brasileira do Oitocentos, Londrina-PR, 2017.

${ }^{19}$ CARVALHO. Op, cit. p. 94.

${ }^{20}$ O Curso Jurídico de Olinda ocupava o primeiro andar do convento e uma sala do térreo. O salão principal da instituição ficava por cima da sacristia e a biblioteca estava localizada no segundo andar. Cf: NASCIMENTO, Alexsandro Ribeiro de. "Sob o Império da Lei: a atuação dos juízes municipais na comarca do Recife (18411850)". Dissertação (Mestrado em História) - Universidade Federal Rural de Pernambuco, Recife. 2014, p. 50

${ }^{21}$ Os promotores públicos tinham a função de denunciar os crimes públicos, e policiais, e acusar os delinquentes perante os Jurados, assim como os crimes de reduzir à escravidão pessoas livres, cárcere privado, homicídio, ou ferimentos com as qualificações dos artigos 202, 203, 204 do Código Criminal; e roubos, calúnias, e injurias contra o Imperador, e membros da Família Imperial, contra a Regência, e cada um de seus membros, contra a Assembleia Geral, e contra cada uma das Câmaras. Nomeado por juízes municipais e posteriormente os de Direito. NEQUETE, Lenine. O poder Judiciário no Brasil a partir da Independência. Brasília: Superior Tribunal Federal. 2000. V. 2. p, 71.

${ }^{22}$ SODRÉ, Elaine Leonara de Vargas. Brasil Imperial: O poder do Estado exercido através da administração judiciária. Anais do X Encontro Estadual de História. Universidade Federal de Santa Maria - UFSM. 2010

${ }^{23}$ SODRÉ. Op, cit.

${ }^{24}$ Entre os autores que analisam o aparato jurídico do oitocentos, Mozart Linhares se destaca pela explanação da ideia de modernidade na formação jurídica imperial e na construção do Código Criminal de 1830. Cf: SILVA, Mozart Linhares da. O Império dos bacharéis: o pensamento jurídico e a organização do Estado-Nação no Brasil. Curitiba: Juruá, 2004.

${ }^{25}$ José Dimas utiliza o caráter mediador do poder judiciário no médio Sertão do São Francisco no século XIX e, através disso, tentou demonstrar os obstáculos que o Estado e o meio jurídico tiveram para implantar as novas leis. BATISTA, Dimas José. A administração da justiça e o controle da criminalidade no Médio Sertão do São Francisco, 1830-1880. Tese (doutorado). São Paulo: Universidade de São Paulo, Programa de pós-graduação em História, 2006. p. 42.

${ }^{26} \mathrm{O}$ juiz dos órfãos tratava e decidia tudo o que dizia respeito a um menor de idade ou pessoas incapacitadas. Ele era guardião dos órfãos e das heranças, solucionando as questões sucessórias a eles ligados. De acordo com a promulgação do Código Criminal em 1832: "Haverá tantos Juízes dos Órfãos, quantos forem os Juízes Municipais, e nomeados pela mesma maneira". Eles podiam atuar também como mediador de arrematação de escravos. Com o decreto o serviço dos africanos deveria ser realizado perante o próprio juiz de órfãos e não mais em praça pública. Seus serviços deveriam ser prestados nos municípios de cada província. Ver Coleção das Leis Império do Brasil 1835. Op. Cit. 1864

${ }^{27}$ Com a Reforma Judiciária de 1871, a justiça deixou de ter os moldes de polícia. A partir de então, a magistratura e a própria polícia iriam ganhar contornos nítidos e próximos das instituições dos tempos atuais. Cf: VARGAS. Op, cit p. 156.

${ }^{28}$ Usamos como método a Micro-História, inspirado na teoria de Carlo Ginzburg sobre indícios e sinais. Para ele, além da análise detalhada (sinais) para alcançar um conhecimento histórico sóbrio é preciso que a narrativa possa ser lida, algumas vezes, "de cabeça para baixo", destacando algumas intenções do autor. O autor precisa se comportar como um detetive. Qualquer vestígio, qualquer sinal pode, muitas vezes, ser considerado um tipo de "pista". Cf: GINZBURG, Carlo. Relações de força: história, retórica, prova. São Paulo. Companhia das Letras. 2002; Já para José D’Assunção Barros a pretensão da Micro-História é reduzir a escala de investigação de observação do historiador e assim analisar aspectos que poderiam passar desapercebidos. O que vale para o historiador não seria a "unidade da observação", mas a "escala de observação" do seu objeto. "Uma vez que em diversas oportunidades ele estará trabalhando ao nível da realidade cotidiana, das trajetórias individuais, das estratégias que circulam sob uma extensa realidade de poderes". Cf: BARROS, José D' Assunção. Sobre a Feitura da Micro-História. OPSIS, vol. 7, nº 9, jul-dez 2007. Pág. 177

${ }^{29} \mathrm{Na}$ historiografia a Praieira é tratada como "revolta", "insurreição", "rebelião" e "revolução", termos explicados por Izabel Marson. No entanto, Marcus de Carvalho aponta que a expressão "insurreição" é clássica e no Código Criminal de 1830 era considerada crime de maior gravidade em relação aos outros termos. Por conta disso, utilizaremos essa expressão. Cf: MARSON, Izabel Andrade. O império do progresso: A revolução 
praieira. São Paulo: Brasiliense, 1987; CARVALHO, Marcus J. M. de. Os nomes da revolução: lideranças populares na Insurreição Praieira, Recife, 1848-1849. Revista Brasileira de História, vol. 23, no 45, p.209-238, jul. 2003.

${ }^{30}$ DIÁRIO DE PERNAMBUCO, Recife. Quarta, 10 de março de 1847. Ed. 56. p, 1-2. Disponível em : http://memoria.bn.br/DocReader/DocReader.aspx?bib=029033_02\&Pesq=Joaquim\%20Villela\&pagfis=8771. Acessado em janeiro de 2020.

31 FACULDADE DE DIREITO DO RECIFE. Projeto Memória Acadêmica. Disponível em: https://www.ufpe.br/memoriafdr/biografias. Acessado em julho de 2019

${ }^{32} \mathrm{Na}$ década de 40 do oitocentos os Cavalcantis era o clã com o maior poder político em Pernambuco. Cf: CADENA, Paulo Henrique Fontes. Ou há de ser Cavalcanti, Ou há de ser Cavalgado. Trajetórias políticas dos Cavalcanti de Albuquerque. (Pernambuco, 1801 - 1844). Recife: EdUFPE, 2013.

${ }^{33}$ DIÁRIO DE PERNAMBUCO. Recife. Quinta, 11 de março de 1847. Ed. 56. Pág. 1-2. Disponível em : http://memoria.bn.br/DocReader/DocReader.aspx?bib=029033 02\&Pesq=Joaquim\%20Villela\&pagfis=8775.

Acessado em janeiro de 2020

${ }^{34}$ FACUldade DE DIREITO DO RECIFE. Anais da Assembleia Legislativa Provincial de Pernambuco. Primeira Sessão de 1846. Pernambuco. Tipografia da província. 1889. p, 20-55. Sessão de 13 de março de 1846, fala do deputado Jeronimo Vilella de Castro Tavares

${ }^{35}$ MARSON. Op, cit. CARVALHO. Op, cit.; MELO, Jerônimo Martiniano Figueira de. Autos do inquérito da Revolução Praieira. Brasília: Senado Federal: Univ. de Brasília, 1979; QUINTAS, Amaro. O Sentido Social da Revolução Praieira. Recife: Ed. Massangana, 1982.

${ }^{36}$ FACULDADE DE DIREITO DO RECIFE. Projeto Memória Acadêmica. Op, cit.

${ }^{37}$ TAVARES, Jeronymo Vilella de Castro. Compendio de Direito Publico Eclesiastico para uso nas Faculdades de Direito do Imperio. Rio de Janeiro. B. L. Garnier, Livreiro-Editor. 3 edição. 1882.

${ }^{38}$ NABUCO, Joaquim. Um Estadista do Império. Volumes I e II. Rio de Janeiro: Topbooks, 1997. p. 378.

${ }^{39}$ NABUCO. Op, cit. p. 403

${ }^{40}$ FACULDADE DE DIREITO DO RECIFE. 1889. p, 35-37. Sessão de 16 de março de 1846, fala do deputado Joaquim Vilella Tavares

${ }^{41}$ Ao contrário da abordagem de Sérgio Adorno sobre o bacharelismo no oitocentos, o ensino jurídico também era significativo no período. Mesmo com atividades extra acadêmicas, sobretudo no campo político, os magistrados eram responsáveis por produções intelectuais que foram importantes para a formação técnica de várias gerações da época. Sobre a discussão de alguns modus operandi do bacharelismo ver em ADORNO, Sérgio. Os Aprendizes do poder. Rio de Janeiro. Paz e Terra. 1988

${ }^{42}$ TAVARES, Joaquim Villela. Instituições de Direito Público Eclesiástico. Tomo I. Recife. Livreiros Editores. 1856. p, 5

${ }^{43}$ TAVARES. Op, cit.

${ }^{44}$ TAVARES. Op, cit. p, 7

${ }^{45}$ FACULDADE DE DIREITO DO RECIFE. 1889. p, 35-37. Sessão de 16 de março de 1846, fala do deputado Joaquim Vilella Tavares

${ }^{46}$ As próprias ideias de Rousseau sobre propriedade era um argumento em prol daqueles que defendiam a escravidão. Segundo o teórico francês, a propriedade era um dos direitos mais sagrados do cidadão, mais importante até, em alguns casos, do que a própria liberdade. Para ele, se a vontade soberana do povo era pela preservação do direito de propriedade, então o direito era legitimo. De acordo com Bobbio, Mattueucci e Pasquino, essa relação entre indivíduo, propriedade e liberdade encontrava relação na teoria da evolução natural, fundamentada na luta pela sobrevivência. Cf: ABREU, Wilame Gomes de. Dos fundamentos à teoria da convenção em Jean-Jacques Rousseau. Tese. Doutorado. Universidade de Goiás. Faculdade de Filosofia (Fafil), Programa de Pós-Graduação em Filosofia. Goiânia. 2019; BOBBIO, Norberto. MATTEUCCI, Nicola. PASQUINO. Dicionário de política. Brasília: Editora. Universidade de Brasília, 1 la ed., 1998. Vol. 1

${ }^{47}$ FACULDADE DE DIREITO DO RECIFE. 1889. p, 35-37. Sessão de 16 de março de 1846, fala do deputado Joaquim Vilella Tavares

48 A UNIÃO, Recife. Sábado.Ed. 112. 19 de maio de 1849. Disponível em: http://memoria.bn.br/DocReader/DocReader.aspx?bib=222658\&Pesq=Joaquim\%20Villela\&pagfis=375.

Acessado em dezembro de 2020

49 O LIBERAL PERNAMBUCANO. Recife. Ed. 77. 13 de dezembro de 1852. p. 1. Disponível em: http://memoria.bn.br/DocReader/DocReader.aspx?bib=705403\&PagFis=305\&Pesq=Joaquim\%20Vilella.

Acessado em julho de 2019. 
50 O LIBERAL PERNAMBUCANO. Recife. Ed. 93. 8 de janeiro de 1853. p, 1. Disponível em: http://memoria.bn.br/DocReader/DocReader.aspx?bib=705403\&PagFis=305\&Pesq=Joaquim\%20Vilella Acessado em julho de 2019.

${ }^{51} \mathrm{O}$ PROGRESSO. Recife. Ed. 27. 20 de março de 1858 . p, 1. Disponível em: http://memoria.bn.br/DocReader/DocReader.aspx?bib=705284\&PagFis=34\&Pesq=Joaquim\%20Vilella. Acessado em julho de 2019

\section{Referências}

ABREU, Wilame Gomes de. Dos fundamentos à teoria da convenção em Jean-Jacques Rousseau. Tese. Doutorado. Universidade de Goiás. Faculdade de Filosofia (Fafil), Programa de Pós-Graduação em Filosofia. Goiânia. 2019.

ADORNO, Sérgio. Os Aprendizes do poder. Rio de Janeiro. Paz e Terra. 1988.

ANTUNES, Álvaro Araújo. As paralelas e o infinito: uma sondagem historiográfica acerca da História da Justiça na América Portuguesa. Revista de História São Paulo, No 169, p. 21-52, julho / dezembro 2013.

BALANDIER. George. O poder em cena. Brasília. UNB. 1982

BARROS, José D' Assunção. Sobre a Feitura da Micro-História. OPSIS, vol. 7, n 9, jul-dez 2007.

BATISTA, Dimas José. A administração da justiça e o controle da criminalidade no Médio Sertão do São Francisco, 1830-1880. Tese (doutorado). São Paulo: Universidade de São Paulo, Programa de pós-graduação em História, 2006.

BEVILÁQUA, Clóvis. História da Faculdade de Direito do Recife. Recife: EdUFPE, 2012.

BICALHO, Maria Fernanda. "Elites coloniais: a nobreza da terra e o governo das conquistas. História e historiografia". In: MONTEIRO, Nuno G. F. et alli (org.). Optma Pars. Elites Ibero-Americanas do Antigo Regime. Lisboa: Imprensa de Ciências Sociais, 2005.

BOBBIO, Norberto. MATTEUCCI, Nicola. PASQUINO. Dicionário de política. Brasília: Editora. Universidade de Brasília, 1 la ed., 1998. Vol. 1.

CADENA, Paulo Henrique Fontes. Ou há de ser Cavalcanti, Ou há de ser Cavalgado. Trajetórias políticas dos Cavalcanti de Albuquerque. (Pernambuco, 1801 - 1844). Recife: Ed. UFPE, 2013.

CADENA, Paulo Henrique Fontes. O vice-rei: Pedro de Araújo Lima e a governança do Brasil no século XIX. Tese (doutorado). UFPE. 2018.

CARVAlHO, José Murilo de. A construção da ordem: a elite política imperial. Rio de Janeiro: Campos. 1980.

CARVALHO, Marcus J. M. de. Os nomes da revolução: lideranças populares na Insurreição Praieira, Recife, 1848-1849. Revista Brasileira de História, vol. 23, no 45, p.209-238, jul. 2003.

COLEÇÃO DAS LEIS IMPÉRIO DO BRASIL 1835. Rio de Janeiro. Tipografia Nacional. 1864.

COLEÇÃO DE LEIS DO IMPÉRIO DO BRASIL 1841 E 1871. Disponível em http://bd.camara.gov.br/bd/handle/bdcamara/18299/browse?type=title

COLEÇÃO DE LEIS DO IMPÉRIO DO BRASIL DE 1831. Rio de Janeiro: Tipografia Nacional, 1878.

DOLHNIKOFF, Mirian. O pacto imperial: origens do federalismo no Brasil do século XIX. São Paulo: Globo. 2005. 
FACULDADE DE DIREITO DO RECIFE. Arquivo. Livro de certidões de idade (1836 1839).

FACULDADE DE DIREITO DO RECIFE. Anais da Assembleia Legislativa Provincial de Pernambuco. Primeira Sessão de 1846. Pernambuco. Tipografia da província. 1889.

FACULDADE DE DIREITO DO RECIFE. Arquivo. Lista geral dos bacharéis e doutores (1828 - 1931).

FACULDADE DE DIREITO DO RECIFE. Arquivo. Livro de certidões de idade (1829 1831).

FACULDADE DE DIREITO DO RECIFE. Arquivo. Livro de certidões de idade (1832 1835).

FACULDADE DE DIREITO DO RECIFE. Arquivo. Livro de registro de diplomas de bacharéis e doutores (1833 - 1925).

FACULDADE DE DIREITO DO RECIFE. Arquivo. Livro de registro de matrículas do $3^{\circ}$ ano $(1830-1868)$.

FACULDADE DE DIREITO DO RECIFE. Projeto Memória Acadêmica. Disponível em: https://www.ufpe.br/memoriafdr/biografias

FERLINI, Vera Lúcia Amaral (orgs.) Modos de Governar. Ideias e Práticas Políticas no Império Português - séculos XVI a XIX. São Paulo. Almeida, 2005.

FREYRE, Gilberto. Sobrados e Mucambos. Rio de Janeiro: Editora Record, 1990.

FUNDAÇÃO BIBLIOTECA NACIONAL. A União. Recife. Disponível em: http://memoria.bn.br/hdb/uf.aspx

FUNDAÇÃO BIBLIOTECA NACIONAL. Diário de Pernambuco. Recife. Disponível em: http://memoria.bn.br/hdb/uf.aspx

FUNDAÇÃO BIBLIOTECA NACIONAL. O Liberal Pernambucano. Recife. Disponível em: http://memoria.bn.br/hdb/uf.aspx

FUNDAÇÃO BIBLIOTECA NACIONAL.. O Atheneu Pernambucano. Recife. Disponível em: http://memoria.bn.br/hdb/uf.aspx

FUNDAÇÃO BIBLIOTECA NACIONAL.. Folhinha do Almanak Administrativo, Mercantil, Industrial e Agrícola. Disponível em: http://memoria.bn.br/hdb/uf.aspx

GINZBURG, Carlo. Relações de força: história, retórica, prova. São Paulo. Companhia das Letras. 2002.

GOUVÊA, Maria de Fátima S. "Redes governativas portuguesas e centralidades régias no mundo português, c. 1680-1640". In: FRAGOSO, João \& GOUVÊA, Maria de Fátima S. Na Trama das Redes. Rio de Janeiro: Civilização Brasileira, 2010.

HEINZ, Flávio M. (org). Por outra história das elites. FVG editora. Rio de Janeiro. 2006;

HEINZ, Flávio. Por outra história das elites. Rio de Janeiro: FGV, 2006

HESPANHA, Antônio Manuel. Da Iustitia à disciplina: textos, poder e política penal no Antigo Regime" Justiça e litigiosidade: História e prospectiva, Lisboa, Fundação Calouste Gulbenkian, 1993.

HESPANHA, Antônio Manuel. Governo, elites e competência social: sugestões para um entendimento renovado da história das elites. In BICALHO, Maria Fernanda. IRUROZQUI, Marta. "Presentación. La institucionalización del Estado en América Latina. Justicia y violência política en la primera mitad del siglo XIX". In: Revista Complutense de Historia de América. 2011, vol. 37.

MARSON, Izabel Andrade. O império do progresso: A revolução praieira. São Paulo: Brasiliense, 1987;

MELO, Jerônimo Martiniano Figueira de. Autos do inquérito da Revolução Praieira. Brasília: Senado Federal: Univ. de Brasília, 1979. 
NABUCO, Joaquim. Um Estadista do Império. Volumes I e II. Rio de Janeiro: Topbooks, 1997.

NASCIMENTO, Alexsandro Ribeiro de. "Sob o Império da Lei: a atuação dos juízes municipais na comarca do Recife (1841-1850)". Dissertação (Mestrado em História) Universidade Federal Rural de Pernambuco, Recife. 2014.

NEQUETE, Lenine. O poder Judiciário no Brasil a partir da Independência. Brasília: Superior Tribunal Federal. 2000. V. 2.

QUINTAS, Amaro. O Sentido Social da Revolução Praieira. Recife: Ed. Massangana, 1982.

SILVA, Mozart Linhares da. O Império dos bacharéis: o pensamento jurídico e a organização do Estado-Nação no Brasil. Curitiba: Juruá, 2004.

SLEMIAN, Andréa. Sob o império das leis: Constituição e unidade nacional na formação do Brasil (1822-1834). Tese. História. USP. São Paulo. 2016.

SODRÉ, Elaine Leonara de Vargas. Brasil Imperial: O poder do Estado exercido através da administração judiciária. Anais do X Encontro Estadual de História. Universidade Federal de Santa Maria - UFSM. 2010.

SOUZA, Laura de Mello. O Sol e a sombra: política e administração da América Portuguesa do século XVIII. São Paulo. Companhia das Letras. 2016.

SPINOSA. Vanessa. "Da simples abnegação de cidadãos: serviço público e o judiciário oitocentista". In: II Encontro Internacional da Sociedade Brasileira do Oitocentos, LondrinaPR, 2017.

SPINOSA. Vanessa. A lei dos homens: formação jurídica e cultura política no brasil império. Passagens. Revista Internacional de História Política e Cultura Jurídica, Rio de Janeiro: vol. 3, no.3, setembro-dezembro 2011, p. 486-502

SPINOSA. Vanessa. Vocação para a justiça: o serviço público como missão cidadã (Brasil1840-1889). Tesis Doctoral. Universidade de Salamanca. Salamanca. 2016.

TAVARES, Jeronymo Vilella de Castro. Compendio de Direito Publico Eclesiastico para uso nas Faculdades de Direito do Imperio. Rio de Janeiro. B. L. Garnier, Livreiro-Editor. 3 edição. 1882.

TAVARES, Joaquim Villela. Instituições de Direito Público Eclesiástico. Tomo I. Recife. Livreiros Editores. 1856.

VARGAS, Jonas Moreira. Entre a paróquia e a Corte: a elite política do Rio Grande do Sul (1850-1869), Santa Maria: UFSM, 2007.

VEIGA, Gláucio. História das ideias da Faculdade de Direito do Recife. Recife. V. 1. Ed. Universitária, 1980. 